Section arose. He pointed out that for a number of years it had been felt by some members of the Philosophy of Science Group who were living in the North of England that they were missing a good deal by not being able to attend its meetings, and it was therefore considered appropriate to have a Section of the Group in their part of the country. Such a Section would help to bring together people interested in the philosophy of science and encourage discussion and research. Inquiries made at Leeds, Liverpool, Sheffield and North Staffordshire as well as Manchester showed that there was considerable interest in the proposal. The members promoting the scheme therefore decided to ask the Philosophy of Science Group for permission to form a Northern Section, and this was readily granted. As far as future activities are concerned, it is hoped to hold meetings at regular intervals at the various university centres taking part in the scheme. There will obviously have to be a good deal of flexibility and decentralisation, and, wherever possible, local centres will be encouraged to organise their own activities.

The resolution to form the Section was then put to the meeting and carried, and it was decided to elect a provisional committee to take charge of the affairs until October, when there will be a general meeting and officers will be elected for the year 1954-55. Prof. D. M. Emmet (professor of philosophy, University of Manchester) was elected provisional chairman of the Section, and Dr. Mays provisional honorary secretary and treasurer. It was resolved that the committee be composed of two representatives from each University, and that members should be elected by the Philosophy of Science Group on the recommendation of the Section. Twenty-eight applications for membership were made at the meeting.

\title{
Rationalism in Antiquity
}

ABSTRACT of Address delivered by Prof. L. Rosenfeld at the Inaugural Meeting of the Northern Branch held at Manchester University on 30th January, 1954.

The growth and development of rationalism in antiquity raises several historical problems which have perhaps not hitherto been sufficiently recognised. The purely philosophical aspect of the remarkable elaboration of a rationalistic view of the world by the presocratic thinkers has received a great deal of attention and can now be regarded as completely elucidated by the work of Paul Tannery and Enriques. The latter especially put into its right light the great figure of Demokritos, whose atomic system represents the culmination of this evolution.

When we try, however, to follow up the development of rationalism after Demokritos, the situation at once becomes obscure. If we compare the views of Epicurus and Lucretius with what we can reconstruct from those of Demokritos, we are struck by the fact that while the scientific content of the system remains very much the same (with only some signs of decay), stronger and stronger emphasis is put on the more human and social problems. Lucretius' atheism, for example, is not merely an intellectual point of view, but a distinctly anti-clerical attitude which, so far as we know, was at any rate not prominent in Demokritos' views. This then raises the first problem that I wish to discuss: how is this change of attitude of the rationalistic philosophers related to the changes of their social environment? For the answer to this question one has not far to seek when one remembers how the Greek world was shaken to its very foundations by the breakdown of the 
Athenian democracy and the following conquest of the Persian empire by Alexander. As the Greeks suddenly enlarged their horizon to a world-wide scale, their economy underwent a complete change which confronted them with new political and social problems. A characteristic repercussion of this turmoil is the apparition of a new literary genre, the utopia, which of course is a convenient medium for social reformers and satirists who are unwilling to risk the displeasure of the authorities. None of these utopias has survived, but we know the names of some authors, the most famous of whom is Euhemeros of Messene. The views of Euhemeros have quite a rationalistic flavour. In particular, his attempt to give a rational interpretation of religious myths is so characteristic that the word euhemerism has been coined to denote this type of rationalisation of religion. It is significant that one of the utopists who influenced Euheremos, Hekataios of Abdera, is described as a disciple of Demokritos. The popularity of Euhemeros' book lasted a long time and was even transmitted to the Romans by a translation due to Ennius.

The preoccupation of the utopists with a rational interpretation of religion was not original with them. The question had already been raised by the Sophists and we find echoes of a similar religious crisis in the two great philosophical currents which developed in Hellenistic times, the Stoic and the Epicurean schools. In fact the conflict between popular religion and philosophical views of God became inevitable in all the great schools to which the development of presocratic philosophy led. The issue came to a crisis when its social implications became more and more prominent in the Hellenistic period. The evolution of rationalism during this period reflects the slow process of gradual decay of ancient society, strikingly illustrated by the contrast between the progressive and optimistic outlook of Demokritos and Lucretius' last pathetic assertion of the power of human reason against the obscurantism which was going to overwhelm it.

Returning now to Demokritos and the evolution leading to him, we may also ask what social preoccupations are apparent among the presocratics and how they can be related to the economic and social background against which their thinking developed. It is indeed possible to trace back the rationalistic analysis of social phenomena to the Milesian school from which the whole body of presocratic philosophy originated. We meet here another Hekataios, who developed for the first time a rational view of history in which he endeavoured to interpret the tales about heroes by the same method Euhemeros later applied to the gods. It has often been pointed out, most convincingly by Professor Farrington, that there is a direct causal connection between the rationalist outlook of presocratic philosophers and the industrial and commercial type of culture to which they belonged. Judging from other well-known examples, this connection does seem to be a historical law of wide validity. The present context offers us a further occasion of testing it. Philosophy did not originate in Miletos. As our knowledge of Oriental sources increases we realise more and more how largely the Ionians were indebted to the Orient for the fundamental features of their systems. As the main carriers of this Oriental tradition one thinks in the first place of the Phenicians. Now, if ever a civilisation was of the commercial and industrial type it was that of the Phenicians. It is therefore of special interest to enquire of what kind their philosophy was. In this enquiry we are unfortunately hampered by the scarcity of the evidence. About all we know of Phenician cosmogony is the indirect evidence associated with the shadowy figure of Sanchuniathon. A convincing case, however, has recently been made by Eissfeldt, on the basis of the archaeological evidence from Ugarit, for the authenticity of the Sanchuniathon tradition. At any rate 
our information concerning him is not worse than most of the doxography pertaining to the presocratics. The rationalistic character of Sanchuniathon's views is very striking indeed, as well as the analogy with those of the Milesian Anaximenes. It therefore seems that we may risk going one more step back towards the origin of rationalism in that commercial civilisation which preceded the Ionian one. It would be wrong, however, to suggest that the Ionians just took over Phenician views. The transmission of philosophical and scientific ideas is never a mere imitation. Even though the general trends may remain essentially the same, the details of the picture must be worked out anew under the influence of ever-changing circumstances.

Looking back on the whole evolution we have endeavoured to reconstruct, we see rationalism at a nascent stage among the Phenicians, revived and developed by the presocratic philosophers, and reaching its acme with Demokritos. The opening-up of the Orient enabled the Greeks to rediscover the Phenician origins of their thinking. Phenician books were actively translated and the ideas they contained were one of the sources of inspiration of the utopists. Together with these, the Epicurean school prolonged the rationalistic tradition, and fought a losing fight for it until the very end of the ancient world.

\section{Action at a Distance}

ABSTRACT of Paper read by Dr. Mary Hesse at the meeting of the Northern Branch held at Leeds University on 13th March, 1954.

A distinction can be made between two sorts of statement in physical science: observation statements which are directly testable by measurement, and those which are not so testable, which may be called non-observational. Statements about the way in which action is communicated between bodies are usually non-observational, and if one considers a statement such as "Action is communicated between the fundamental particles of matter by their mutual impacts", one can suggest four possible answers to the question of what is the logical status of this statement in physics :

(i) The realist view that it is a straightforward description of empirical fact.

(ii) The view that it is meaningless because it is non-observational. This is hardly held seriously by anyone, because it would reject as meaningless most of the statements of theoretical physics.

(iii) The formalist view that it can only be given meaning by interpreting it into a mathematical calculus from which observation statements can be deduced.

(iv) The view that it is an analogical description which shows what model from macroscopic experience is being used to describe small-scale phenomena.

To determine the logical status of a scientific statement one must examine the way in which it is used in its scientific context, and in the case of action at a distance, it is necessary to examine the history of the concept.

From the seventeenth century to the advent of modern physics three types of fundamental actions were recognised, each exemplified by models drawn from familiar experience, and each describable by a definite mathematical calculus. The three types are action by impact, action in a continuous medium, 